\title{
The ionospheric response in the Brazilian sector during the super geomagnetic storm on 20 November 2003
}

\author{
F. Becker-Guedes ${ }^{1}$, Y. Sahai ${ }^{1}$, P. R. Fagundes ${ }^{1}$, E. S. Espinoza ${ }^{2}$, V. G. Pillat ${ }^{1}$, W. L. C. Lima ${ }^{3}$, Su. Basu ${ }^{4}$, Sa. Basu ${ }^{5}$, \\ Y. Otsuka ${ }^{6}$, K. Shiokawa ${ }^{6}$, E. M. MacKenzie ${ }^{7}$, X. Pi ${ }^{8}$, and J. A. Bittencourt ${ }^{9}$ \\ ${ }^{1}$ Universidade do Vale do Paraiba (UNIVAP), São José dos Campos, SP, Brazil \\ ${ }^{2}$ Radio Observatorio de Jicamarca, Instituto Geofisico del Peru, Lima, Peru \\ ${ }^{3}$ Centro Univ. Luterano de Palmas (CEULP), Universidade Luterana do Brasil (ULBRA), Palmas, TO, Brazil \\ ${ }^{4}$ Center for Space Physics, Boston University, Boston, MA, USA \\ ${ }^{5}$ Space Vehicles Directorate, Air Force Research Laboratory, Hanscom AF Base, MA, USA \\ ${ }^{6}$ STELAB, Nagoya University, Toyokawa, Japan \\ ${ }^{7}$ Institute for Scientific Research, Boston College, Chestnut Hill, MA, USA \\ ${ }^{8}$ Jet Propulsion Laboratory, California Institute of Technology, Pasadena, CA, USA \\ ${ }^{9}$ Instituto Nacional de Pesquisas Espaciais (INPE), São José dos Campos, SP, Brazil
}

Received: 21 November 2006 - Revised: 26 February 2007 - Accepted: 30 March 2007 - Published: 8 May 2007

\begin{abstract}
A very intense geomagnetic storm (superstorm) began with storm sudden commencement (SSC) at 08:03 UT on 20 November 2003, as a result of the coronal mass ejection (CME) by sunspot 484 hurled into space on 18 November 2003. The geomagnetic storm attained $\left|D_{s t}\right|_{\max }=472 \mathrm{nT}$ at 20:00 UT (20 November). In this paper we present the simultaneous ionospheric sounding observations, using the Canadian Advanced Digital Ionosondes (CADIs), carried out from Palmas (PAL; $10.2^{\circ} \mathrm{S}, 48.2^{\circ} \mathrm{W}$; dip latitude $5.5^{\circ} \mathrm{S}$; a near equatorial station) and São José dos Campos (SJC; $23.2^{\circ} \mathrm{S}, 45.9^{\circ} \mathrm{W}$; dip latitude $17.6^{\circ} \mathrm{S}$; station located under the crest of equatorial ionospheric anomaly), Brazil. In addition, total electron content (TEC) measurements from several GPS receiving stations in the Brazilian sector during this storm are presented. The simultaneous ionospheric sounding observations carried out at SJC and PAL, and TEC observations on 3 consecutive days viz., 19 November (quiet), 20 November (disturbed) and 21 November (recovery phase) are presented. Salient features from the ionospheric observations in the Brazilian sector during the superstorm are discussed. The difference in the observed ionospheric response at the two stations (PAL and SJC) is considerable. This is not surprising given that PAL is close to the magnetic equator and SJC is near the crest of the equatorial ionospheric anomaly (EIA). It should be pointed out that soon after the SSC (about $4 \mathrm{~h}$ later), the F-region critical frequency $(f o \mathrm{~F} 2)$, the F-region peak height $(h p \mathrm{~F} 2)$, and variations of virtual heights at different frequencies (iso-frequency plots) all show
\end{abstract}

Correspondence to: F. Becker-Guedes

(fabio@univap.br) wavelike oscillations of the F-region during daytime at both the ionospheric sounding stations. Unusual rapid uplifting of F-region at PAL was observed during both the main and recovery phases of the storm.

Keywords. Ionosphere (Equatorial ionosphere; Ionospheremagnetosphere interactions; Ionospheric irregularities)

\section{Introduction}

The response of ionosphere-thermosphere system in the equatorial and low latitude region during super geomagnetic storms or superstorms (we have considered a geomagnetic storm with $\left|D_{s t}\right|_{\max }>250 \mathrm{nT}$ as superstorm) are important space weather issues. Geomagnetic storms are extreme forms of space weather disturbances. Geomagnetic storm effects on ionospheric regions covering high, mid and low latitude have been reviewed by several investigators (e.g., Danilov and Morozova, 1985; Schunk and Sojka, 1996; Abdu, 1997; Buonsanto, 1999). However, investigations related to magnetosphere-ionosphere interactions during geomagnetic storms at equatorial and low latitude continue to attract considerable attention because more case studies are needed to understand better different types of space weather events and increase our capability to predict ionospheric responses. As discussed by Abdu (1997) response of the equatorial ionosphere to magnetospheric disturbances are produced by electric fields (prompt equatorward penetration of magnetospheric/high latitude electric field (e.g., Senior and Blanc, 1984; Spiro et al., 1988), and ionospheric disturbance

Published by Copernicus GmbH on behalf of the European Geosciences Union. 


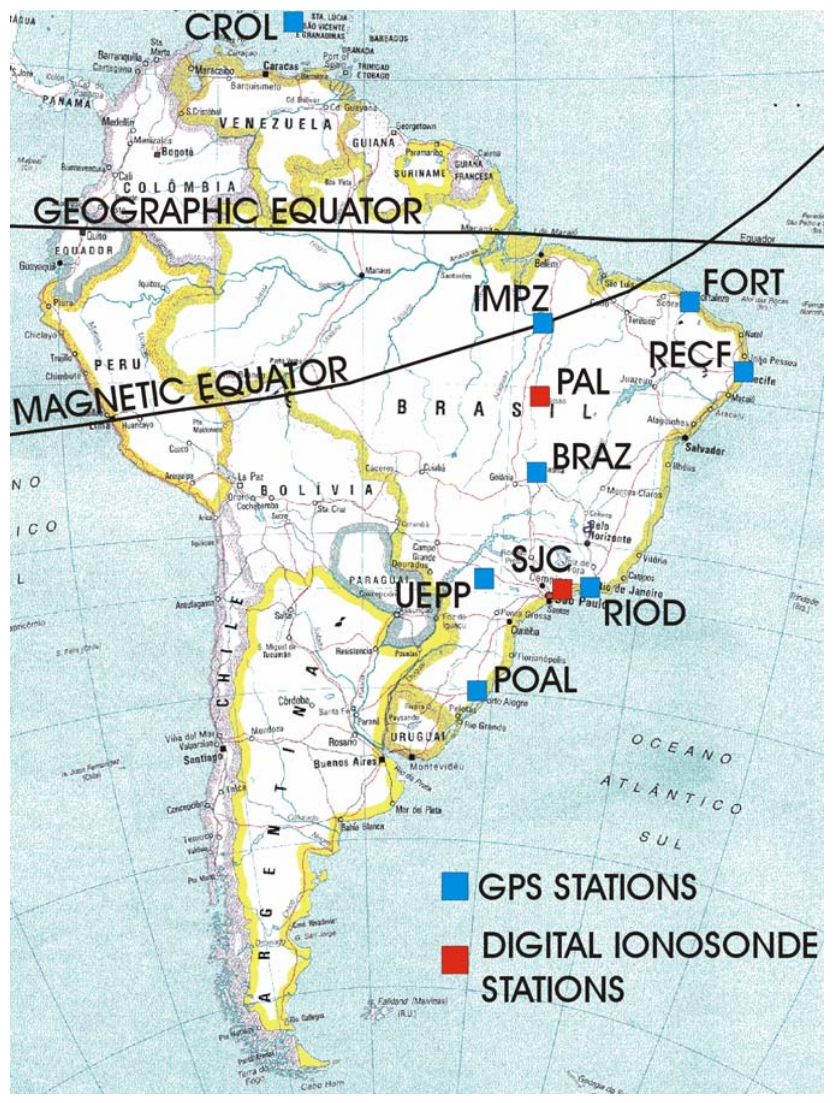

Fig. 1. Map of South America showing the locations of the ionospheric sounding and GPS receiving stations. Also, the geographic and magnetic equators are shown.

dynamo due to global thermospheric wind circulation associated with Joule heating at high latitude (e.g., Blanc and Richmond, 1980). Other possible perturbations could be caused by winds (transport of energy from high latitudes in form of changes in global wind pattern and traveling atmospheric disturbances due to Joule heating or Lorentz forces; e.g. Burns and Killeen, 1992; Hajkowicz, 1990; Prolss, 1997; Nicolls et al., 2004) and composition changes (changes in the thermospheric composition $\left(\mathrm{O} / \mathrm{N}_{2}\right)$ ratio; e.g. Greenspan et al., 1991; Zhang et al., 2003).

As mentioned by Gopalswamy et al. (2005) the largest geomagnetic storm of solar cycle 23 occurred on 20 November 2003, due to a coronal mass ejection (CME) from active region 501 that erupted near the center of the sun on 18 November 2003, evolved into an interplanetary magnetic cloud and hit Earth's magnetic field on 20 November. This impact resulted in a superstorm with a storm sudden commencement (SSC) at 08:03 UT (20 November) attaining $\left|D_{s t}\right|_{\max }=472 \mathrm{nT}$ at 20:00 UT (20 November). In this paper we present and discuss the simultaneous ionospheric sounding observations carried out from Palmas $\left(10.2^{\circ} \mathrm{S}, 48.2^{\circ} \mathrm{W}\right.$; dip latitude $6.6^{\circ} \mathrm{S}$; a near equatorial station and hereafter re-

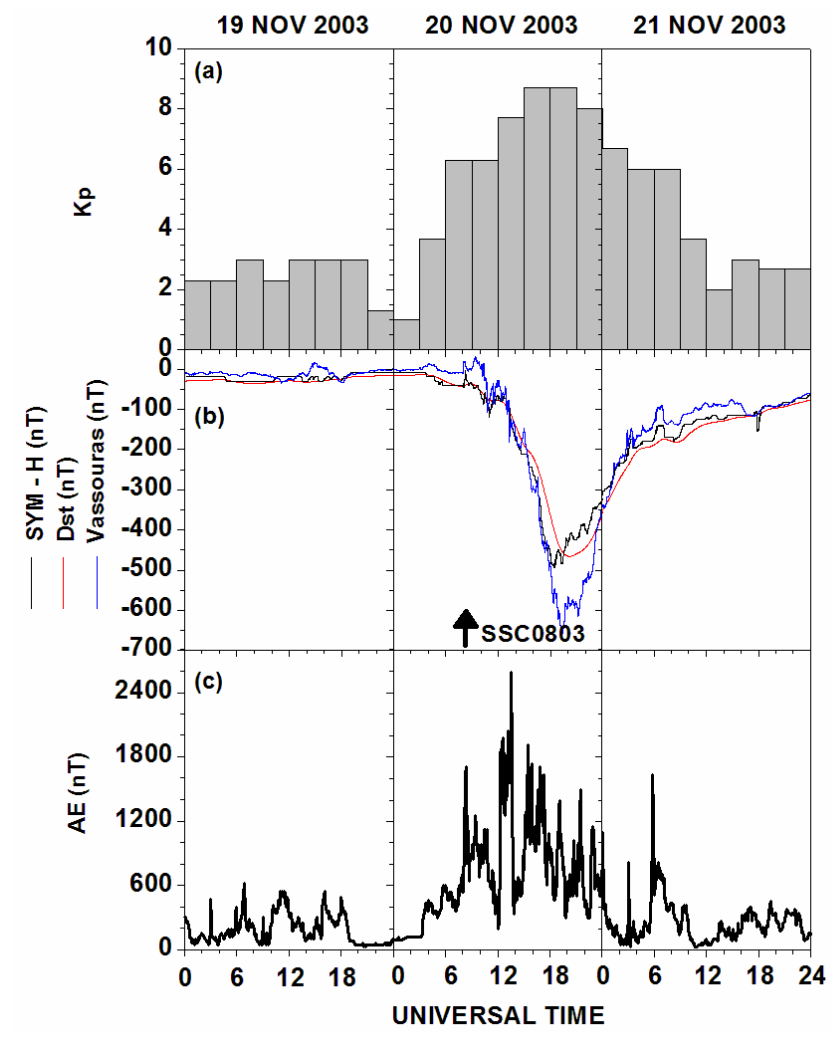

Fig. 2. The variations of the $K_{p}, D_{s t}, \mathrm{SYM}-\mathrm{H}$ and AE geomagnetic indices during the period 19-21 November 2003. Also, the geomagnetic field $\mathrm{H}$-component variations during the period 19-21 November 2003, observed at Vassouras, Brazil, are shown.

ferred as PAL) and São José dos Campos $\left(23.2^{\circ} \mathrm{S}, 45.9^{\circ} \mathrm{W}\right.$; dip latitude $18.6^{\circ} \mathrm{S}$; a low-latitude station located under the southern crest of the equatorial ionospheric anomaly and hereafter referred as SJC), Brazil, and total electron content (TEC) measurements from several GPS receiving stations in the Brazilian sector, except one station which is located in the Central American sector, during this storm. The two ionospheric sounding stations are located nearly in the meridian (geomagnetic) direction separated by about $1460 \mathrm{~km}$ and are equipped with the Canadian Advanced Digital Ionosonde (CADI) (Grant et al., 1995). It should be mentioned that several other workers (e.g. Meier et al., 2005; Bruinsma et al., 2006; Crowley et al., 2006) have also investigated the response of thermosphere and/or ionosphere to this superstorm.

\section{Observations}

The two ionospheric sounding stations (PAL and SJC) have same the local time, with UT=LT+3h. Table 1 presents the details of all the Global Positioning System (GPS) stations from which data have been utilized in the present study. All the GPS stations belong to the "Rede Brasileira 
Table 1. Details of the GPS receiving sites used in the study.

\begin{tabular}{llllll}
\hline Location & $\begin{array}{l}\text { Symbol used } \\
\text { (Network) }\end{array}$ & $\begin{array}{l}\text { Geog. } \\
\text { Lat. }\end{array}$ & $\begin{array}{l}\text { Geog. } \\
\text { Long. }\end{array}$ & Dip Lat. & Local Time (LT) \\
\hline St. Croix, U.S. (Virgin Is.) & $\begin{array}{l}\text { CROL } \\
\text { (IGS) }\end{array}$ & $17.8^{\circ} \mathrm{N}$ & $64.6^{\circ} \mathrm{W}$ & $25.9^{\circ} \mathrm{N}$ & $\mathrm{LT}=\mathrm{UT}-4 \mathrm{~h}$ \\
Fortaleza, Brazil & $\begin{array}{l}\text { FORT } \\
\text { (IGS/RBMC) }\end{array}$ & $3.8^{\circ} \mathrm{S}$ & $38.4^{\circ} \mathrm{W}$ & $7.1^{\circ} \mathrm{S}$ & $\mathrm{LT}=\mathrm{UT}-3 \mathrm{~h}$ \\
Imperatriz, Brazil & $\begin{array}{l}\text { IMPZ } \\
\text { (RBMC) }\end{array}$ & $5.5^{\circ} \mathrm{S}$ & $47.5^{\circ} \mathrm{W}$ & $2.9^{\circ} \mathrm{S}$ & $\mathrm{LT}=\mathrm{UT}-3 \mathrm{~h}$ \\
Brasilia, Brazil & $\begin{array}{l}\text { BRAZ } \\
\text { (IGS/RBMC) }\end{array}$ & $15.9^{\circ} \mathrm{S}$ & $47.9^{\circ} \mathrm{W}$ & $11.7^{\circ} \mathrm{S}$ & $\mathrm{LT}=\mathrm{UT}-3 \mathrm{~h}$ \\
Recife, Brazil & $\begin{array}{l}\text { RECF } \\
\text { (RBMC) }\end{array}$ & $8.0^{\circ} \mathrm{S}$ & $34.9^{\circ} \mathrm{W}$ & $13.1^{\circ} \mathrm{S}$ & $\mathrm{LT}=\mathrm{UT}-3 \mathrm{~h}$ \\
Presidente Prudente, Brazil & $\begin{array}{l}\text { UEPP } \\
\text { (RBMC) }\end{array}$ & $22.1^{\circ} \mathrm{S}$ & $51.4^{\circ} \mathrm{W}$ & $14.9^{\circ} \mathrm{S}$ & $\mathrm{LT}=\mathrm{UT}-3 \mathrm{~h}$ \\
Rio de Janeiro, Brazil & $\begin{array}{l}\text { RIOD } \\
\text { (RBMC) } \\
\text { POAL } \\
\text { Porto Alegre, Brazil }\end{array}$ & $22.8^{\circ} \mathrm{S}$ & $43.3^{\circ} \mathrm{W}$ & $19.8^{\circ} \mathrm{S}$ & $\mathrm{LT}=\mathrm{UT}-3 \mathrm{~h}$ \\
& $30.1^{\circ} \mathrm{S}$ & $51.1^{\circ} \mathrm{W}$ & $20.7^{\circ} \mathrm{S}$ & $\mathrm{LT}=\mathrm{UT}-3 \mathrm{~h}$ \\
\hline
\end{tabular}

de Monitoramento Continuo (RBMC; Brazilian Network for Continuous GPS Monitoring)" operated by the "Instituto Brasileiro de Geografia e Estatística (IBGE; Brazilian Institute of Geography and Statistics)", except the station St. Croix, U.S. Virgin Island, which belongs to the International GPS Service (IGS) for Geodynamics. Figure 1 shows the locations of the ionospheric sounding and GPS stations used in the present investigations. Figure 2 shows the UT variations in $K_{p}$ (Fig. 2a; intensity of storms; 3-hourly values), $D_{s t}$ (Fig. $2 \mathrm{~b}$; intensity of the ring current; hourly values), SYM-H (Fig. 2b; 1-min resolution $D_{s t}$ values; http: //swdcwww.kugi.kyoto-u.ac.jp), and AE (Fig. 2c; intensity of the auroral electrojet; every 1 min values) geomagnetic indices during the period 19-21 November 2003. Also, Fig. 2b shows the geomagnetic field $\mathrm{H}$-component variations during the period 19-21 November 2003 (UT days), observed at Vassouras $\left(22.4^{\circ} \mathrm{S}, 43.6^{\circ} \mathrm{W}\right.$; dip latitude $\left.19.3^{\circ} \mathrm{S}\right)$, Brazil.

Figures 3 and 4 show variations of the ionospheric parameters minimum virtual height of the F-layer $\left(h^{\prime} \mathrm{F}\right.$; black dots), critical frequency ( $f o \mathrm{~F} 2$; black dots), and $h p \mathrm{~F} 2$ (the virtual heights at $0.834 f o \mathrm{~F} 2$ (black dots) - a proxy for the peak F-layer height $(h m \mathrm{~F} 2))$ for the UT days 19 November (quiet), 20 November (geomagnetically disturbed) and 21 November (recovery phase) 2003, observed at PAL and $\mathrm{SJC}$, respectively. The ionospheric parameters reported were obtained every $15 \mathrm{~min}$. It should be mentioned that during the main phase of the superstorm on 20 November (between about 12:00 UT to 20:00 UT), the ionograms at PAL were of relatively poor quality. The ionospheric parameters from the ionograms, which were incomplete (partial), have been omitted in Fig. 3. Crosses (Fig. 3) show the ionograms, which needed extreme care and extrapolation in scaling to get the ionospheric parameters. Also, Figs. 3 and 4 show the median values of the ionospheric parameters $\left(\mathrm{h}^{\prime} \mathrm{F}, f_{o} \mathrm{~F} 2\right.$ and $h p \mathrm{~F} 2$; red line) for both the stations on 10 quiet days (classification available through the website http://ftp.gwdg.de/pub/geophys/kp-ap/tab/), every $15 \mathrm{~min}$ on $3,5,7,8,19,26,27,28,29$, and 30 November 2003. The quiet day variations in $\mathrm{h}^{\prime} \mathrm{F}$ at PAL (Fig. 3 - red line) show prominent post-sunset pre-reversal enhancement. The absences of $f o \mathrm{~F} 2$ and $h p \mathrm{~F} 2$ values in median plots at PAL during the pre-midnight sector are due to the presence of strong spread-F on the quiet nights.

As pointed out by Danilov and Morozova (1985) the determination of the peak F-layer height $(h m \mathrm{~F} 2)$ using $h p \mathrm{~F} 2$ is less reliable during the daytime (the altitude $h p \mathrm{~F} 2$ is overestimated with respect to the true altitude of the maximum of the layer $h m \mathrm{~F} 2$ ) than at nighttime where $h p \mathrm{~F} 2 \approx h m \mathrm{~F} 2$. As reported by Batista et al. (1991), $h p \mathrm{~F} 2$ could differ from $h m \mathrm{~F} 2$ by $\leq 50 \mathrm{~km}$ during daytime and by $\leq 10 \mathrm{~km}$ during nighttime. However, in the present investigation, the main aim is to study variations of F-region height observed during geomagnetically disturbed period relative to the quiet time patterns, it is reasonable to use the ionospheric parameter $h p \mathrm{~F} 2$ even during daytime. Figure 5 shows a set of ionogram combinations obtained at times separated by about $30 \mathrm{~min}$ at PAL and SJC on 20 November, which included the main phase of the superstorm. Figure 6 shows the observed variations of virtual heights at different fixed reflection frequencies (measurements every $100 \mathrm{~s}$ ) at PAL (top panel) and SJC (bottom panel) during the period 19 to 21 November 2003 (UT days). It is seen in Fig. 6 that the absorption of radio waves ( $<7 \mathrm{MHz}$ at PAL and $<5 \mathrm{MHz}$ at SJC) similar to 20 November are also present on 19 November (quiet day) and 


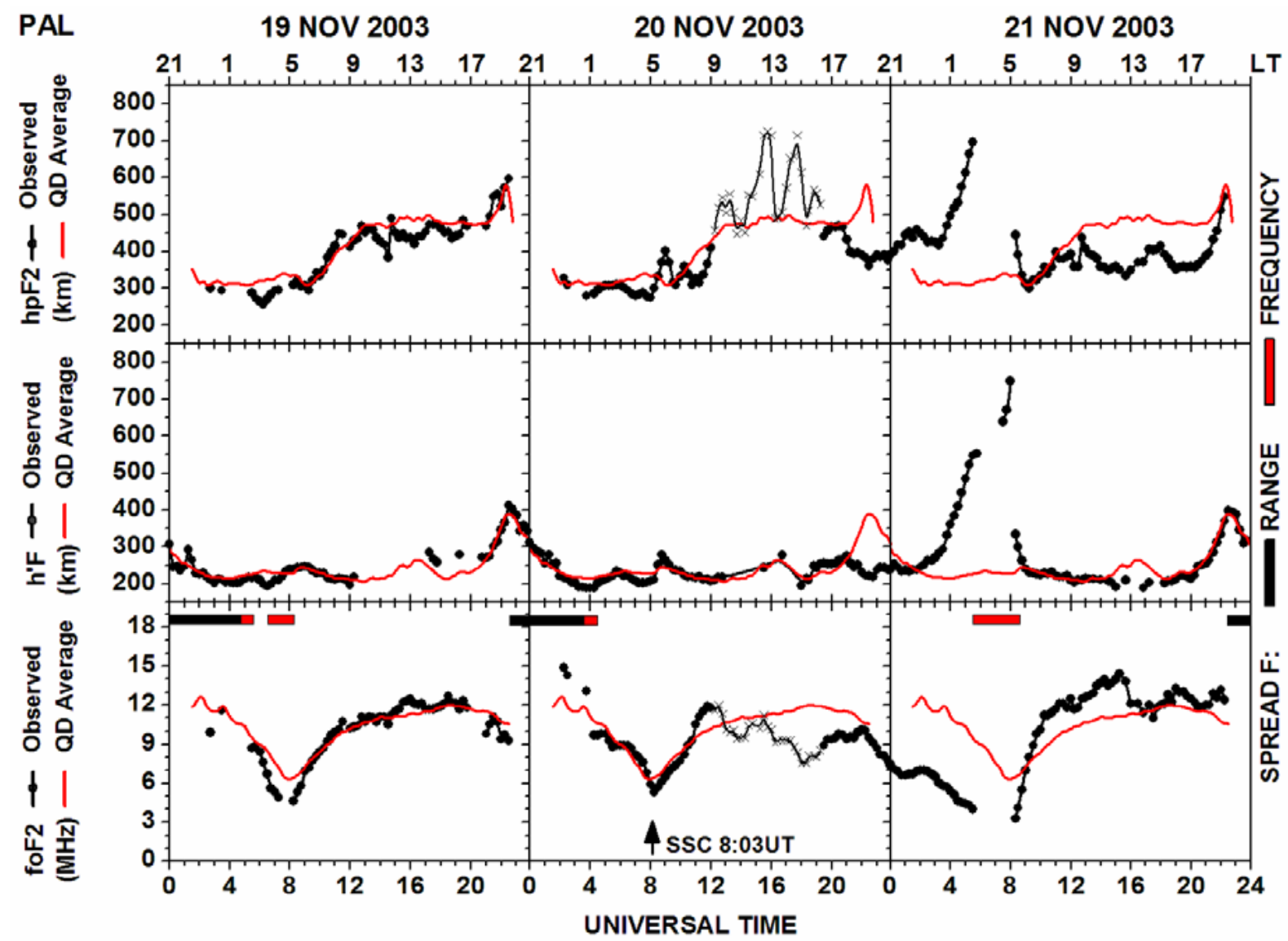

Fig. 3. The variations of $h^{\prime} \mathrm{F}, f o \mathrm{~F} 2$ and $h p \mathrm{~F} 2$ (black dots with line) during the period 19-21 November 2003 observed at Palmas (PAL), Brazil. The average quiet-day variations of $\mathrm{h}^{\prime} \mathrm{F}, h p \mathrm{~F} 2$ and $f o \mathrm{~F} 2$ (red line) are also shown.

21 November (period of recovery) (Fig. 2). Therefore, it appears the low frequency absorption of radio waves in ionosphere is not associated with the storm-time effects.

Figure 7 shows the average (every $5 \mathrm{~min}$ ) vertical total electron content (VTEC) UT variations from GPS observations (satellites above $30^{\circ}$ elevation angle) at 8 receiving stations (Table 1) during the period 19 to 21 November 2003. Figure 8 shows the phase fluctuations (rate of change of TEC (TEC/min); see e.g. Aarons et al., 1996) from GPS signals obtained from different satellites at 2 receiving stations, aligned fairly close to the PAL-SJC geomagnetic meridian, during the period 19 to 21 November 2003 (UT days). As mentioned by Mendillo et al. (2000) the TEC changes presented encompass, potentially, the entire path in the F-region. Figure 9 shows several "Global Ionospheric Maps" using the IGS GPS stations produced by "CODE (Center for Orbit Determination in Europe; website - http://www.aiub.unibe.ch/ionosphere.html), observed on 19 November (quiet) and 20 November (geomagnetically disturbed) 2003 between 10:00 UT and 20:00 UT (every $2 \mathrm{~h}$ ).

\section{Results and discussion}

During intense geomagnetic disturbances, profound changes are observed in the F-region height (e.g. $\mathrm{h}^{\prime} \mathrm{F}$ and $h p \mathrm{~F} 2$ ) and plasma densities in the low latitude region and these are important diagnostics for storm-time effects. In general, geomagnetic storms are described by an SSC (sometimes gradual commencement) followed by initial or growth, main and recovery phases. As mentioned by Schunk and Sojka (1996), during the growth phase, the magnetospheric electric field and particle precipitation patterns expand, the electric fields become stronger and precipitation becomes more intense, however, the energy input to the upper atmosphere maximizes during the main phase, while during the recovery phase the geomagnetic activity and energy input decreases. It should be pointed out that, during a storm if the electron density increases as a result of storm dynamics, it is called "positive ionospheric storm or positive phase", while a decrease in electron density is called "negative ionospheric storm or negative phase" (Danilov and Morozova, 1985; Schunk and Sojka, 1996). For storm-time effects associated with the low latitude ionosphere, Abdu (1997) has pointed out that 


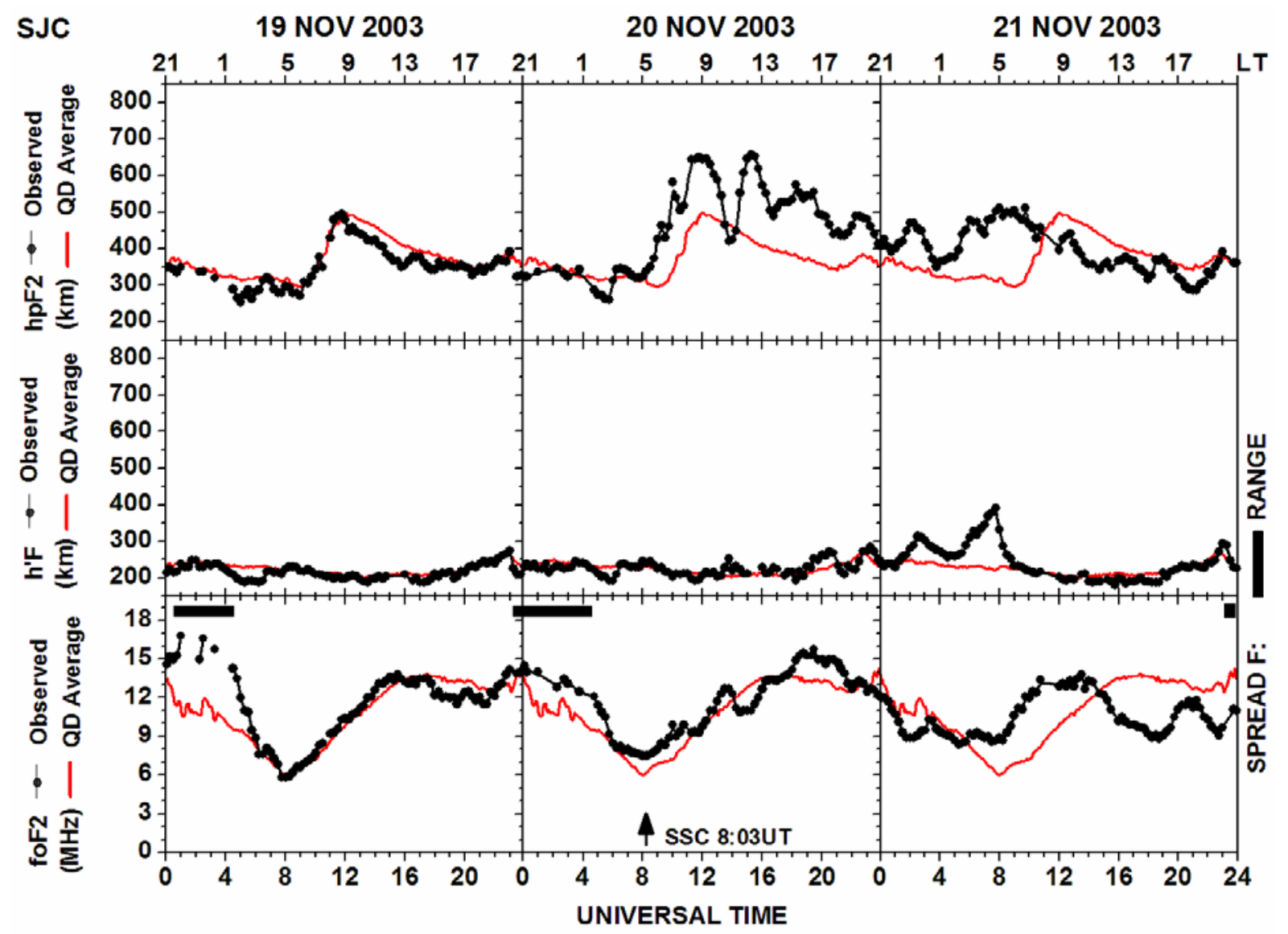

Fig. 4. Same as in Fig. 3, but for Sao Jose dos Campos (SJC), Brazil.

there are two major sources, that is disturbance electric fields and disturbance winds, however, sometimes a mix up of the two effects are possible (e.g. Reddy and Nishida, 1992; Abdu, 1997). The principal features observed in the F-region ionospheric parameters during the superstorm starting on 20 November with SSC at 08:03 UT are presented and discussed in this section.

\subsection{Observed wave like structures}

The variations of $f o \mathrm{~F} 2$ at $\mathrm{PAL}$ and $\mathrm{SJC}$, during the period 19-21 November, are shown in Figs. 3 and 4. Both stations show oscillations over the quiet day average starting at about 12:00 UT. SJC shows peak enhancement around 19:00 UT on 20 November, whereas PAL shows a minimum around the same time. The global ionospheric TEC maps (Fig. 9) also show large spatial variations, on the disturbed day compared with quiet day starting around 12:00 UT and anomalous east-west aligned equatorial ionization anomaly arcs between 18:00 to 20:00 UT, close to the Brazilian sector. Recently, Bruinsma et al. (2006) have studied the thermospheric density response to this geomagnetic storm from accelerometer measurements on the CHAMP and GRACE satellites (be- tween about 400 and $550 \mathrm{~km}$ ). They have reported that, in a global sense, density increases of the order of $300-800 \%$ occur with only about 4-h delay at the equator. Possibly the unusual $f_{o} \mathrm{~F} 2$ response observed at PAL and SJC during the disturbed period is associated with the large thermospheric density reported by Bruinsma et al. (2006).

The F-region height $\left(\mathrm{h}^{\prime} \mathrm{F}\right.$ and $\left.h p \mathrm{~F} 2\right)$ variations at PAL and SJC are shown in Figs. 3 and 4, respectively. Figure 6 shows the iso-frequency plots at PAL and SJC. A perusal of height changes observed at PAL and SJC in Figs. $3(h p \mathrm{~F} 2), 4(h p \mathrm{~F} 2)$ and 6, show the start of oscillating behavior, compared with observations on 19 November and quiet days average, only about two hours after the SSC (08:03 UT on 20 November). This period is very short for TIDs generated by geomagnetic disturbance to reach this low latitude station. Possibly these oscillations are associated with local tropospheric disturbances. However, from about 12:00 UT on 20 November both PAL and SJC (Figs. 3, 4 and 6) show large height oscillations which are possibly associated with the traveling ionospheric disturbances (TIDs). During this storm, Bruinsma et al. (2006) have reported large-scale $(\geq 1000 \mathrm{~km})$ wave structures with wave speeds $1000-1500 \mathrm{~m} / \mathrm{s}$. Figure 5 shows few (six) combination of ionograms (separated by about 


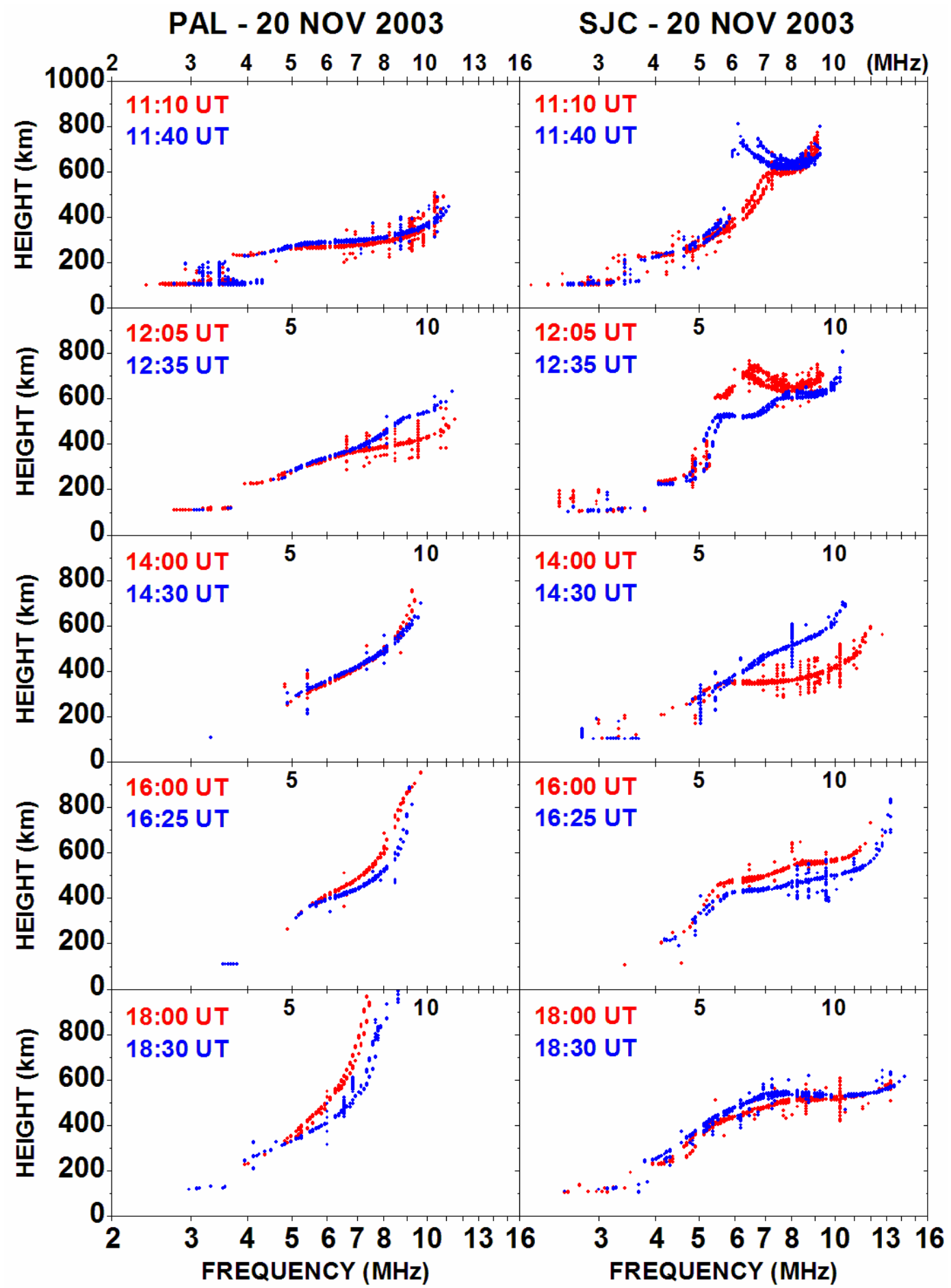

Fig. 5. A set of ionogram combinations obtained at times separated by about $30 \mathrm{~min}$ at PAL and SJC on 20 November, which included the main phase of the superstorm.

half-hour) obtained at PAL and SJC during about 11:40 UT18:30 UT on 20 November. These combinations of ionograms clearly show the effect of TIDs on the F-region at these equatorial and low latitude regions.
3.2 Unusual F-region height and peak electron density changes

Figure 6 shows an unusually rapid height rise of the F-region at PAL slightly after 16:00 UT on 20 November. In the 


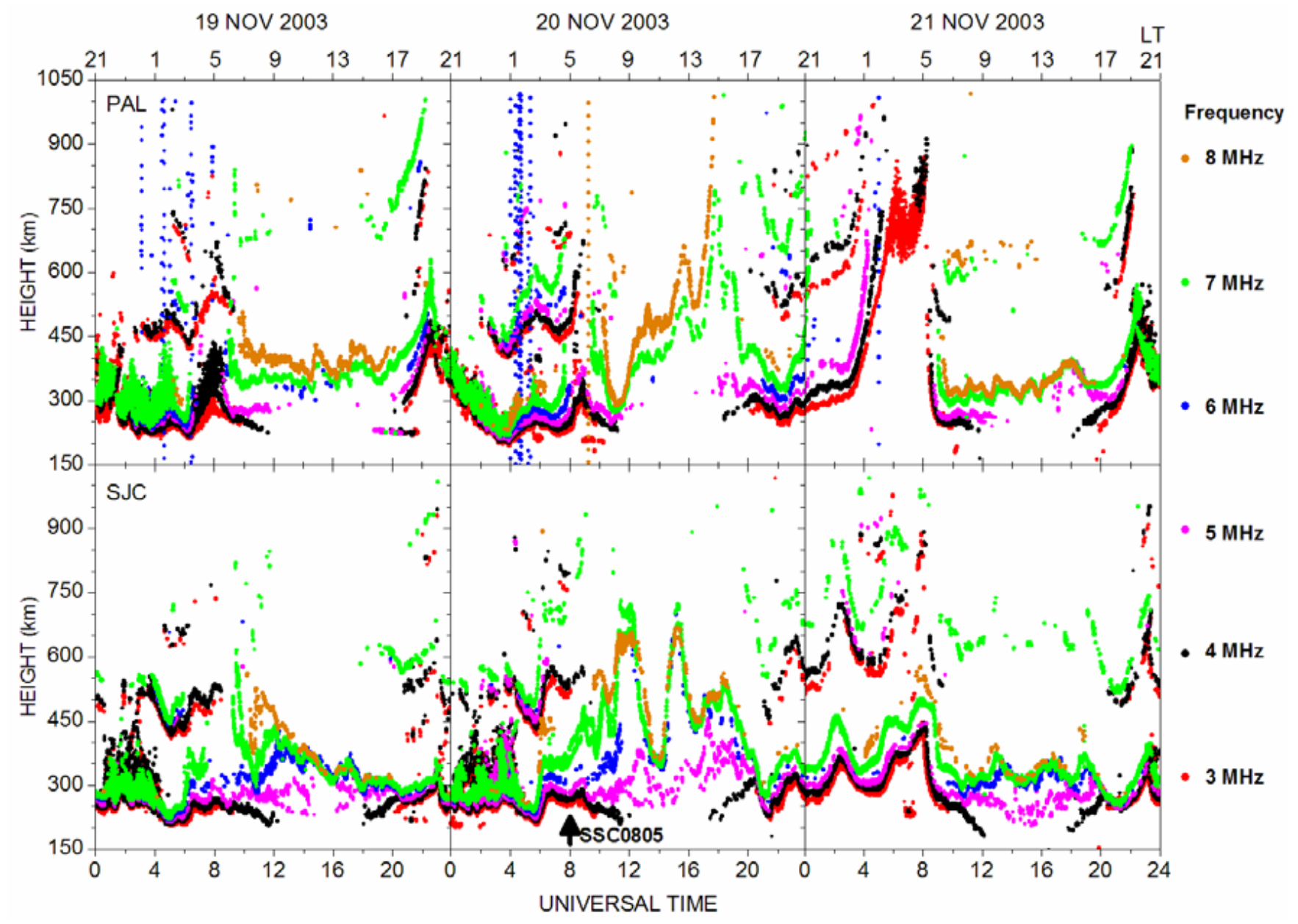

Fig. 6. Virtual height variation plots for different fixed frequencies (iso-frequencies) for the period 19 to 21 November, 2003 , observed at PAL (top) and SJC (bottom).

main phase, when rapid changes in the $D_{s t}$ index occurs, prompt equatorward penetration of magnetospheric electric field takes place (Wygant et al., 1998; Basu et al., 2001). During the period 16:00 to 19:00 UT on 20 November, the $D_{s t}$ index (Fig. 2; see also SYM-H index) was decreasing rapidly at about $-80 \mathrm{nT} / \mathrm{h}$ and the prompt penetration electric field resulted in rapid height increase at PAL close to 16:00 UT. This uplifting of the F-layer in the equatorial region (Fig. 6) and diffusion of the ionospheric plasma to low latitude regions is clearly seen in Figs. 7 and 9. Figure 7 shows large VTEC enhancements at CROL in the Northern Hemisphere and POAL in the Southern Hemisphere around 20:00 UT. Figure 9 shows an unusual development of the equatorial ionization anomaly arcs during 18:00 to 20:00 UT, as mentioned earlier.

The variations in $\mathrm{h}^{\prime} \mathrm{F}$ at PAL (Fig. 3) show that during the post-sunset period on 20 November, the disturbed day, the pre-reversal enhancement was suppressed. As mentioned by Abdu (1997), this could be associated with the disturbance zonal winds, which are important at the magnetic equator near sunset. Unlike the nights of 18-19 November, 19-20 November and 21-22 November (see Figs. 3, 4 and 8), no large-scale ionospheric irregularities (ESF) developed on this night due to suppression of the pre-reversal enhancement. However, soon after the pre-reversal time, Fig. 3 shows that both $\mathrm{h}^{\prime} \mathrm{F}$ and $h p \mathrm{~F} 2$ variations at PAL undergo rapid uplifting of the F-layer starting at about 03:00 UT on 21 November associated with the penetration of high latitude electric field. This uplifting of the F-layer at PAL is accompanied with a strong decrease in $f o \mathrm{~F} 2$ (SJC during this period shows a little increase in $f o \mathrm{~F} 2$ (Fig. 4)) and generation of frequency type spread-F (Fig. 3). These small-scale irregularities are not seen in Fig. 8. The uplifting of the F-layer at PAL around mid-night local time, is possibly due to storm time vertical drift during an increase in the AE index in the recovery phase of the magnetic storm (Fig. 2) (Fejer and Emmert, 2003; Keskinen et al., 2006). Also, there is an uplifting at SJC, but the amplitude is somewhat small. 


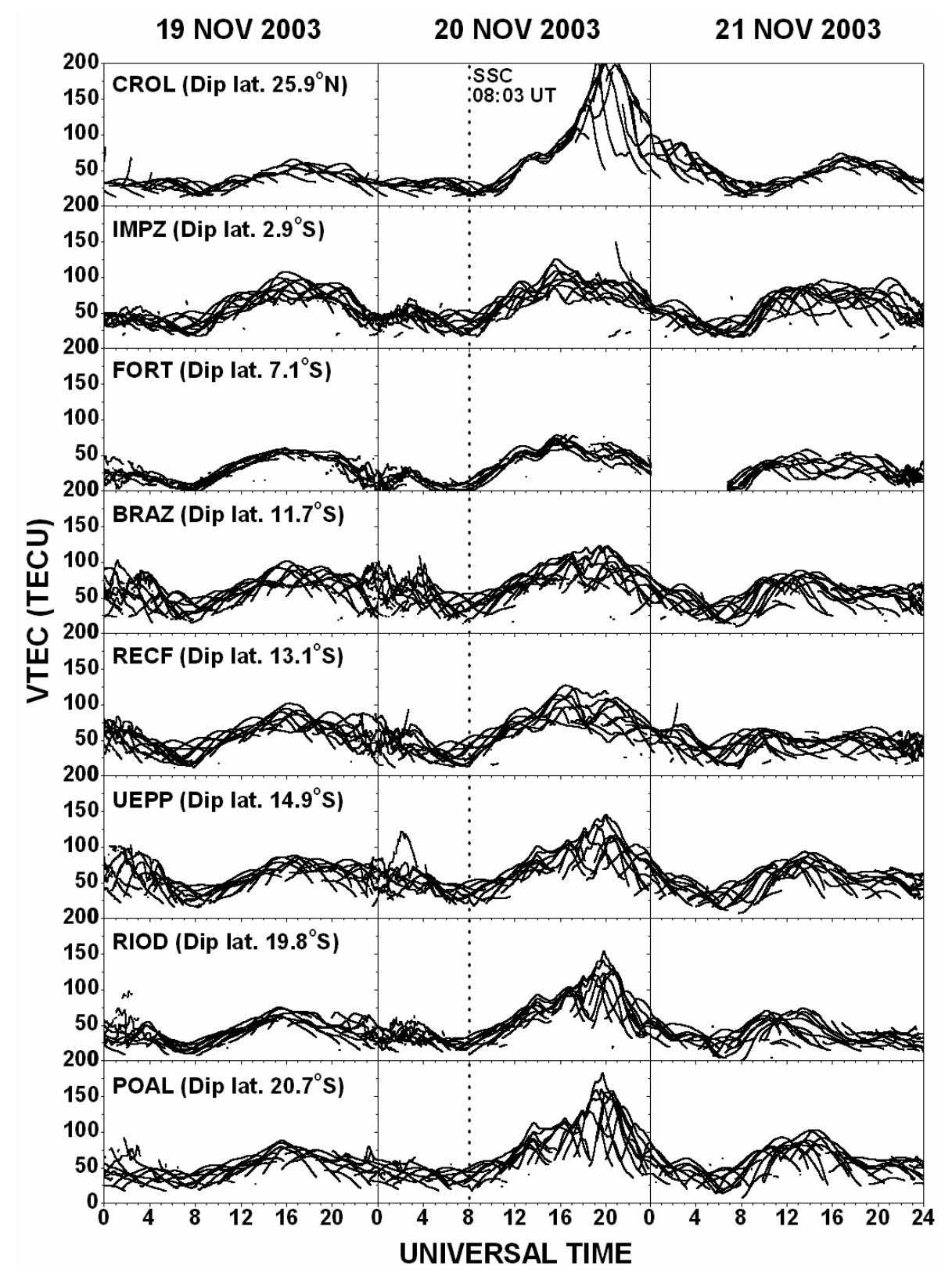

Fig. 7. The vertical total electron content (VTEC) variations from GPS observations (satellites above $30^{\circ}$ elevation angle) at 8 receiving stations (Table 1) during the period 19 to 21 November 2003.

Around 08:00 UT on 21 November, both PAL and SJC (Figs. 3 and 4) show that $f o \mathrm{~F} 2$ starts increasing due to sunrise. Thereafter, both the stations show positive phase. Around 15:00 UT at PAL and around 14:00 UT at SJC, the increasing phase in $f o \mathrm{~F} 2$ turns to decreasing phase. This could be associated with a depletion in the atomic oxygen $(\mathrm{O})$ to molecular nitrogen $\left(\mathrm{N}_{2}\right)$ density ratio. Meier et al. (2005) have studied this superstorm with Global Ultraviolet Imager (GUVI) observations on-board the Thermosphere Ionosphere Mesosphere Energetics and Dynamics (TIMED) satellite. Figure 2 of Meier et al. (2005) shows maps of GUVI O/N 2 ratio and it is observed that on 21 November severe depletions extend to the Brazilian sector. The negative phase in the $f o \mathrm{~F} 2 \mathrm{ob}-$ servations PAL and SJC are in accord with the depletions in GUVI O/N 2 ratio.

\subsection{Comparison with the Halloween storm}

Sahai et al. (2005) have studied the effects of the superstorm at the end of October 2003, also known as the Halloween storm, on the equatorial and low-latitude F-region in the Brazilan sector. During the Halloween storm, the important 


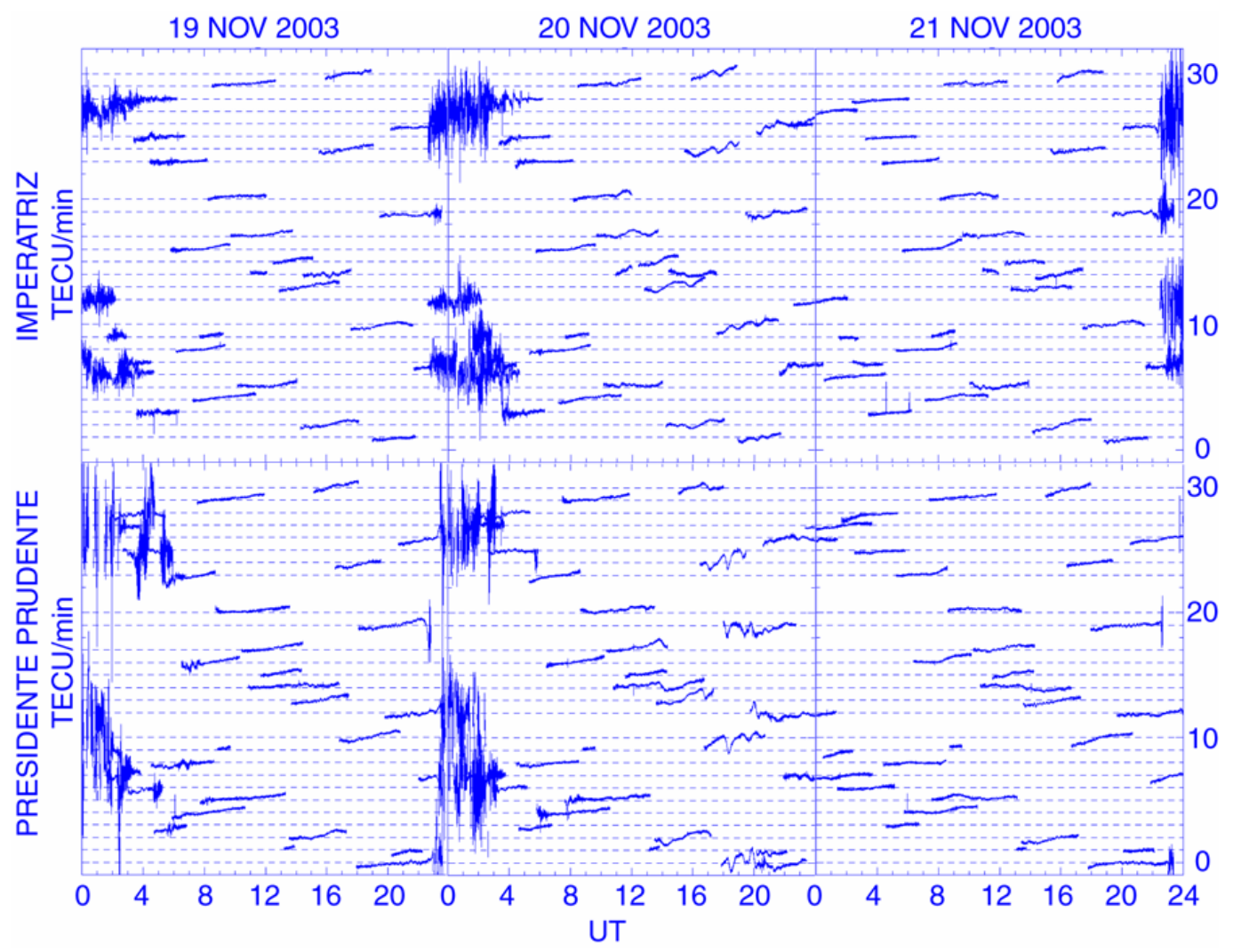

Fig. 8. The phase fluctuations (rate of change of TEC (TEC/min)) from GPS signals obtained from different satellites at 2 receiving stations (Imperatriz and Presidente Prudente, Brazil).

features observed were spectacular uplifting of the F-region during pre-reversal time on both the nights of 29-30 and 3031 October resulting in strong ESF, and unusual development of the equatorial ionospheric anomaly during early morning hours on 29 October (see also Batista et al., 2006). However, during the 20 November storm the unusual uplifting of the F-region was observed in the daytime and there was suppression of the pre-reversal enhancement with no ESF generation. It should be mentioned that during this storm another uplifting of the F-layer with ESF was observed in the recovery phase around the local midnight of 20-21 November. Therefore, there are major differences in the effects of the two superstorms and more case studies will be important for space weather investigations.

\section{Conclusions}

In this paper we have presented the simultaneous ionospheric sounding observations from to stations Palmas (PAL) and São José dos Campos (SJC) located in the Brazilian sector, during the superstorm on 20 November 2003. Data from several GPS receiving stations in the Brazilian longitude zone are also presented. Some of the salient features associated with these observations are summarized below.
1. Only after about $4 \mathrm{~h}$ from the SSC, observations from both ionospheric sounding stations show wavelike structures (fast TIDs).

2. Ionospheric sounding observations at PAL show an unusual lifting of the F-region at about 16:00 UT. The "VTEC" observations at stations away from the magnetic equator show unusually high TEC values at about 20:00 UT, indicating development of strong fountain effect during the storm main phase.

3. At PAL, the variations in $h^{\prime} F$ show considerable reduction in the post-sunset pre-reversal enhancement. No ESF was observed during the early night of 20-21 November 2003.

4. At about 03:00 UT on 21 November 2003, the F-region at PAL shows a strong uplifting with decrease in $f o \mathrm{~F} 2$ resulting in generation of ESF (frequency type) during the storm recovery phase.

5. Both positive and negative effects in $f o \mathrm{~F} 2$ are observed during the storm-time at PAL and SJC.

6. The global ionosphere maps show strong spatial variations and unusual enhancements on 20 November 2003 compared with 19 November 2003. 


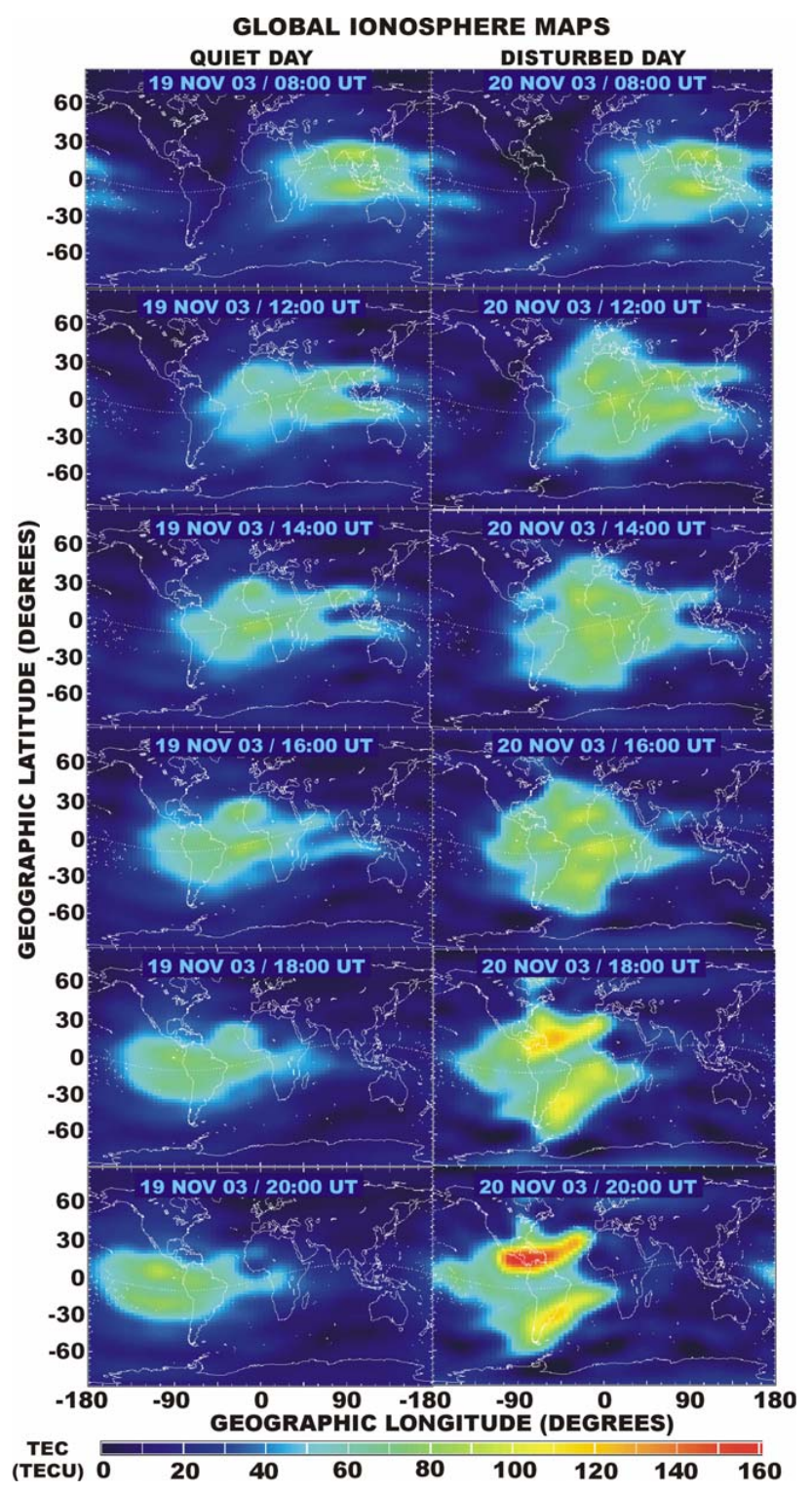

Fig. 9. "Global Ionospheric Maps" using the IGS GPS stations observed on 19 November (quiet) and 20 November (geomagnetically disturbed) 2003 between 10:00 UT and 20:00 UT (every 2 h).

Acknowledgements. The work was partially supported by grants from the Brazilian funding agencies CNPq and FAPESP. We would like to thank the authorities of IBGE, Brazil, for kindly allowing us to use the GPS data obtained by RBMC and Ronaldo Marins de Carvalho, Observatório Nacional, Rio de Janeiro, for kindly providing the magnetometer observations carried out at Vassouras, Brazil. The global ionosphere maps were obtained from the website of the Center for Orbit Determination in Europe (CODE). Su. Basu acknowledges the support of the Office of Naval Research. Sa. Basu and E. M. Mackenzie acknowledge the support of the Air Force Office of Scientific Research task 2301AS. The research conducted at the Jet Propulsion Laboratory, California Institute of Technology, is under a contract with the National Aeronautics and Space Administration, USA.
Topical Editor M. Pinnock thanks M. H. Reilly and another referee for their help in evaluating this paper.

\section{References}

Aarons, J., Mendillo, M., and Yantosca, R.: GPS phase fluctuations in the equatorial region during the MISETA 1994 campaign, J. Geophys. Res., 101, 26 851-26 862, 1996.

Abdu, M. A.: Major phenomena of the equatorial ionospherethermosphere system under disturbed conditions, J. Atmos. Sol. Terr. Phys., 59, 1505-1519, 1997.

Batista, I. S., Abdu, M. A., Souza, J. R., Bertoni, F., Matsuoka, M. T., Camargo, P. O., and Bailey, G. J.: Unusual early morning development of the equatorial anomaly in the Brazilian sector during the Halloween magnetic storm, J. Geophys. Res., 111, A05307, doi:10.1029/2005JA011428, 2006.

Basu, Su., Basu, S., Valladares, C. E., Yeh, H.-C., Su, S.-Y., Mackenzie, E., Sultan, P. J., Aarons, J., Rich, F. J., Doherty, P., Groves, K. M., and Bullet, T. W.: Ionospheric effects of major magnetic storms during the International Space Weather Period of September and October 1999: GPS observations, VHF/UHF scintillations, and in situ density structures at middle and equatorial latitudes, J. Geophys. Res., 106, 30 389-30 413, 2001.

Batista, I. S., de Paula, E. R., Abdu, M. A., and Trivedi, N. B.: Ionospheric effects of the March 13, 1989 magnetic storm at low and equatorial latitudes, J. Geophys. Res., 96, 13 943-13952, 1991.

Blanc, M. and Richmond, A. D.: The ionospheric disturbance dynamo, J. Geophys. Res., 85, 1669-1686, 1980.

Bruinsma, S., Forbes, J. M., Nerem, R. S., and Zhang, X.: Thermospheric density response to the 20-21 November 2003 solar geomagnetic storm from CHAMP and GRACE accelerometer data, J. Geophys. Res., 111, A06303, doi:10.1029/2005JA011284, 2006.

Buonsanto, M. J.: Ionospheric storms - A review, Space Sci. Rev., 88, 563-601, 1999.

Burns, A. G. and Killeen, T. L.: The equatorial neutral thermosphere response to geomagnetic forcing, Geophys. Res. Lett., 19, 977-980, 1992.

Crowley, G., Hackert, C. L., Meier, R. R., Strickland, D. J., Paxton, L. J., Pi, X., Mannuci, A., Christensen, A. B., Morrison, D., Bust, G. S., Roble, R. G., Curtis, N., and Wene, G.: Global thermosphere-ionosphere response to onset of 20 November 2003 magnetic storm, J. Geophys. Res., 111, A10S18, doi:10.1029/2005JA011518, 2006.

Danilov, A. D. and Morozova, L. D.: Ionospheric storms in the $\mathrm{F}_{2}$ region. Morphology and Physics (Review), Geomag. Aeron., 25, 593-605, 1985.

Fejer, B. G. and Emmert, J. T.: Low-latitude ionospheric disturbance electric field effects during the recovery phase of the 1921 October 1998 magnetic storm, J. Geophys. Res., 108(A12), 1454, doi:10.1029/2003JA010190, 2003.

Gopalaswamy, N., Yashiro, S., Michalek, G., Xie, H., Lepping, R. P., and Howard, R. A.: Solar source of the largest geomagnetic storm of cycle 23, Geophys. Res. Lett., 32, L12S09, doi:10.1029/2004GL021639, 2005.

Grant, I. F., MacDougall, J. W., Ruohoniemi, J. M., Bristow, W. A., Sofko, G. J., Koehler, J. A., Danskin, D., and Andre, D.: Comparison of plasma flow velocities determined by the ionosonde 
Doppler drift technique, SuperDARN radars, and patch motion, Radio Sci., 30, 1537-1549, 1995.

Greenspan, M. E., Rasmussen, C. E., Burke, W. J., and Abdu, M. A.: Equatorial density depletions observed at $840 \mathrm{~km}$ during the great magnetic storm of March 1989, J. Geophys. Res., 96, 13 931-13 942, 1991.

Hajkowicz, L. A.: A global study of large scale traveling ionospheric disturbances (TIDS) following a step-like onset of auroral substorms in both hemispheres, Planet. Space. Sci., 38, 913923, 1990.

Keskinen, M. J., Ossakow, S. L., Fejer, B. G., and Emmert, J.: Evolution of equatorial ionospheric bubbles during a large auroral index increase in the recovery phase of a magnetic storm, J. Geophys. Res., 111, A02303, doi:10.1029/2005JA011352, 2006.

Meier, R. R., Crowley, G., Strickland, D. J., Christensen, A. B., Paxton, L. J., Morrison, D., and Hackeert, C. L.: First look at the 20 November superstorm with TIMED/GUVI: Comparisons with a thermospheric global circulation model, J. Geophys. Res., 110, A09S41, doi:10.1029/2004JA010990, 2005.

Mendillo, M., Lin, B., and Aarons, J.: The application of GPS observations to equatorial aeronomy, Radio Sci., 35(3), 885-904, 2000.

Nicolls, M. J., Kelley, M. C., Coster, A. J., Gonzalez, S. A., and Makela, J. J.: Imaging the structure of a large-scale TID using ISR and TEC data, Geophys. Res. Lett., 31, L09812, doi:10.1029/2004019797, 2004.

Prolss, G. W.: Magnetic storm associated perturbations of the upper atmosphere, in: Magnetic Storms, edited by: Tsurutani, B. T., Gonzales, W. D., Kamide, Y., and Arballo, J. K., volume 98 of Geophys. Monogr., 227-241, 1997.
Reddy, C. A. and Nishida, A.: Magnetospheric substorms and nighttime height changes of the F2 region at middle and low latitudes, J. Geophys. Res., 97, 3039-3061, 1992.

Sahai, Y., Fagundes, P. R., Becker-Guedes, F., Bolzan, M. J. A., Abalde, J. R., Pillat, V. G., de Jesus, R., Lima, W. L. C., Crowley, G., Shiokawa, K., MacDougall, J. W., Lan, H. T., Igarashi, K., and Bittencourt, J. A.: Effects of the major geomagnetic storms of October 2003 on the equatorial and low-latitude F region in two longitudinal sectors, J. Geophys. Res., 110, A12S91, doi:10.1029/2004JA010999, 2005.

Schunk, R. W. and Sojka, J. J.: Ionosphere-thermosphere space weather issues, J. Atmos. Terr. Phys., 58, 1527-1574, 1996.

Senior, C. and Blanc, M.: On the control of magnetospheric convection by the spatial distribution of ionospheric conductivities, J. Geophys. Res., 89, 261-284, 1984.

Spiro, R. W., Wolf, R. A., and Fejer, B. G.: Penetration of highlatitude-electric-field effects to low latidudes during SUNDIAL 1984, Ann. Geophys., 6, 39-50, 1988, http://www.ann-geophys.net/6/39/1988/.

Wygant, J., Rowland, D., Singer, H. J., Temerin, M., Mozer, F., and Hudson, M. K.: Experimental evidence on the role of the large spatial scale electric field in creating the ring current, J. Geophys. Res., 103, 29 527-29 544, 1998.

Zhang, Y., Paxton, L. J., Kil, H., Meng, C. -I., Mende, S. B., Frey, H. U., and Immel, T. J.: Negative ionospheric storms seen by the IMAGE FUV instrument, J. Geophys. Res., 108(A9), 1343, doi:10.1029/2002JA009797, 2003. 